\title{
Early life programming as a target for prevention of child and adolescent mental disorders
}

\author{
Andrew James Lewis ${ }^{1 *+}$, Megan Galbally ${ }^{2 \dagger}$, Tara Gannon ${ }^{1+}$ and Christos Symeonides ${ }^{3+}$
}

\begin{abstract}
This paper concerns future policy development and programs of research for the prevention of mental disorders based on research emerging from fetal and early life programming. The current review offers an overview of findings on pregnancy exposures such as maternal mental health, lifestyle factors, and potential teratogenic and neurotoxic exposures on child outcomes. Outcomes of interest are common child and adolescent mental disorders including hyperactive, behavioral and emotional disorders. This literature suggests that the preconception and perinatal periods offer important opportunities for the prevention of deleterious fetal exposures. As such, the perinatal period is a critical period where future mental health prevention efforts should be focused and prevention models developed. Interventions grounded in evidence-based recommendations for the perinatal period could take the form of public health, universal and more targeted interventions. If successful, such interventions are likely to have lifelong effects on (mental) health.
\end{abstract}

Keywords: Child and adolescent mental health, Developmental origins (DOHaD), Fetal programming, Maternal mental health, Obesity, Prevention, Teterogenic exposures

\section{Introduction}

In recent years, a new understanding of the relationship between the early environment and later psychiatric disorder has emerged as the new frontier of psychiatric research. Such research has been largely inspired by the developmental origins of health and disease (DOHaD) model, which proposes a link between fetal development and non-communicable diseases emerging in adulthood such as cardiovascular disease and diabetes [1]. Applying the $\mathrm{DOHaD}$ model to research focused on the etiology of mental disorders has yielded some exciting findings. However, translation of these findings to prevent the development of mental disorders has yet to realize the full potential promised by such discoveries. Fundamental to this translational goal is the integration of prevention science, and so this paper aims to provide a review on what may be gained by linking this new understanding of early development to efforts aimed at preventing mental disorders in children and adolescents.

\footnotetext{
*Correspondence: andrew.lewis@deakin.edu.au

†Equal contributors

'School of Psychology, Faculty of Health, Deakin University, Melbourne, Australia

Full list of author information is available at the end of the article
}

It is well established that the initial onset of high prevalence behavioral and emotional mental disorders frequently commences in childhood or adolescence. Epidemiological studies of population prevalence show rates of child and adolescent mental health disorders to be consistently between $13 \%$ and $20 \%$ [2-4]. National surveys typically assess common mental disorders in childhood and adolescence across the categories of hyperactive, emotional and behavioral disorders. National prevalence studies in Australia and the US have found that attention deficit hyperactivity disorder (ADHD) is the most prevalent mental health disorder among children and adolescents, followed by emotional and behavioral problems $[4,5]$.

Notably, prevalence rates for mental disorders increase significantly as the child ages and also vary markedly by gender. Gender differences become particularly pronounced in relation to pubertal development. For instance, prior to puberty boys are up to twice as likely as girls to present with hyperactivity and behavioral problems, whereas over the pubertal transition girls become two to three times more likely to present with depressive symptoms than boys [5-8]. The relationship between pubertal development and mental health disorders suggests there may be complex interactions between early developmental 
platforms established within the first 1,000 days of life and later pubertal development. Gender differences in neurodevelopmental pathways may be programmed early in life via placental and fetal biology but this has attracted relatively little attention as a source of possible gender differences in mental disorders [9].

\section{Early life programming}

The fetal origins of adult disease model was originally proposed by Barker to explain the observed associations between undernutrition of the fetus, low birth weight (defined as birth weight less than 2,500 grams) and an increased risk of cardiovascular disease, diabetes and metabolic syndrome in later life [10]. Low birth weight was initially considered to be the primary indicator of altered fetal development within this model, although other measures of fetal growth later emerged as equally relevant. With the addition of other epidemiological findings such as the role of preconception maternal body composition and under nutrition, as well as the role of processes that do not impact on fetal weight or growth, the model has been expanded to include events beginning prior to conception as well as in early postnatal life. To reflect the developmental aspects of this model, it is now referred to as the DOHaD [11]. The specific programming, in the form of epigenetic programming, cell distribution, and establishment of endocrine systems and metabolic activity, is thought to vary according to the timing, type, dosage and duration of various environmental exposures across early development - now often referred to as the first 1,000 days of life [12].

The DOHaD model draws on a number of evolutionary concepts, the broadest of which is the notion of life history. This idea suggests that the timing of development is a target of genetic adaption such that, across generations, species will adapt to produce the optimal timing and duration for the development of their reproductive life course [13]. The timing and duration of life history traits such as birth, puberty, first reproduction, gestation and onset of senescence, as well as rate of fetal growth and number and size of offspring are all subject to selection pressure [14]. However, within the individual's life course, greater flexibility is required so each member of a species displays some capacity for developmental plasticity, adjusting the course and timing of development to match prevailing environmental conditions [15-17]. In theory, multiple phenotypes could be produced during development from a single genotype and epigenetic mechanisms are thought to underpin such developmental plasticity [18]. For instance, DNA methylation discordance in epigenomic profiles across a number of different tissues has been observed within monozygotic twin pairs, although dizygotic pairs show an even greater amount of discordance [19]. Developmental plasticity suggests that the capacity to respond adaptively to future environmental conditions enhances the chances of survival and reproductive fitness. This suggests that development is a process where an organism is not only responding to current environmental conditions, but it is also using such information to predict future environmental conditions. Earlier periods of development in the fetal and early infancy period provide indications of the most likely future conditions at a time when there is the greatest degree of plasticity in development. So it follows that the fetal period is regarded as a crucial determinate of whether an organism sets its developmental pathway according to expectations of adversity, stress and high challenge, or develops with expectations of a more benign environment [11].

Fetal programming, therefore, refers to the way in which environmental events alter the course of fetal development, resulting in enduring modifications in the structure and function of biological systems. Programming refers to the influence of a specific environmental factor at a specific point in development, which creates an enduring effect that may result in a bias towards a certain response to subsequent environmental inputs at a later point in development. The work of Meaney and colleagues has been informed by the analogous concept of hormonal imprinting, and they have mapped the role of hormonal signals operating in pregnancy or early postnatal interactions that are able to alter the sensitivity of certain target tissues, often via altered expression of hormone receptors, to these same hormones in later development [20]. It should be noted, however, that the life course of each species will be shaped to emphasize some periods as more or less critical than others. The human life course, for example, has been shaped by a trade-off between bipedalism and gestational length such that the neonatal and early infancy period is one of high vulnerability and plasticity. Furthermore, human puberty as the immediate precursor to reproductive maturation is another period of major biological programming.

These concepts developed within the DOHaD framework can also be used to inform a novel model of vulnerability to mental disorder. Disease and disorder is conceptualized in the $\mathrm{DOHaD}$ model in terms of a mismatch between early programming and later environmental conditions. Depending on later environmental inputs, what may have been 'adaptive' in the intrauterine environment may prove to be the basis of disease in a future postnatal environment. Equally, the early programming of behavior may prove to be a poor fit to later psychosocial norms, educational expectations or interpersonal demands. In the context of such a model, the psychiatric concept of disorder should be considered not simply as a pathological deviation from normality but as a mismatch across development between early programming and later attempts to adapt to prevailing environmental conditions [10]. Schlotz 
et al. applied the mismatch concept to ADHD, for example. They noted that, in an ancestral environment, early developmental indicators that the environment was going to be harsh or rapidly changing would encourage development of a vigilant individual who is ready to respond quickly to new stimuli and so be better adapted to an unpredictable environment [21]. In a modern context, when an individual developing along this trajectory is placed in a modern educational environment that demands long periods of sustained attention and high levels of concentration, the 'response ready' phenotype would be maladaptive.

The DOHaD model is increasingly informed by the emerging understanding of the epigenetic processes that program fetal development. Epigenetic processes do not alter the nucleotide sequence but are responsive to cues from both genes and the environment. Epigenetic programming of fetal and infant development is extremely complex but it does appear that certain exposures can alter epigenetic programming. The most frequently investigated epigenetic processes to date are DNA methylation and histone modification, which play a fundamental role in differentiation of cell structure and function during embryogenesis [22]. Emerging evidence suggests that epigenetic programming continues with significant dynamism across the early postnatal period, with one recent longitudinal study using a genome-wide study of DNA suggesting that one-third of methylation sites show dynamic methylation from birth to 18 months [23] This has led to considerable interest in research examining how altered epigenetic profiles might mediate links between specific intrauterine and early postnatal exposures and future mental health outcomes [22].

\section{The DOHaD model and child mental health outcomes}

An early application of the DOHaD model to mental health outcomes was Barker et al.'s use of the Hertfordshire sample to examine rates of adult suicide as a function of birth weight and growth in the first year. They found that birth weight was not itself predictive but that the average weight of 12-month-old infants was over 400 grams lower in cases of suicide [24]. A significant body of research applying the $\mathrm{DOHaD}$ model has now examined both birth weight and more specific environmental exposures as predictors of child and adolescent mental disorders [21,25,26].

Since dysregulation of the stress response is a common feature of both emotional and behavioral disorders of childhood and adolescence, mental health researchers have focused much of their attention on factors within fetal development that might impact on the postnatal function of the stress response system. Links between vulnerability to mental disorder and fetal programming of metabolic functioning and immune response have also been investigated but to a lesser extent. Specifically, there has been considerable focus on the early development of the hypothalamic-pituitary-adrenal (HPA) system, which is also linked to maturation of other systems responsible for the regulation of circadian rhythms, physical growth and the integration of limbic-cortical processes. As such, the HPA system plays a critical part not only in stress regulation but also in sleep, feeding, emotions and emotionregulation [27]. Animal models exposing pregnant mothers to various types of stress or adversity show a clear impact on the development of the offspring HPA system, that manifests in emotional and behavioral disturbances such as fearfulness, impulsivity and substance use. However, it should be noted that the species-specific ontology of the HPA system is important to consider when applying such findings to humans, since exposures at different points in fetal development may influence various systems involved in neuroendocrine and autonomic responses to stressors and the specific timing and degree of fetal HPA development varies considerably across mammalian species.

The development of the HPA axis in the human fetus is a complex process involving maturation of fetal organs as well as interaction with placental and maternal endocrine systems [28]. In late pregnancy, a rise in fetal cortisol levels is necessary to stimulate the development of organ systems such as the lungs. However, it seems clear that an excess of fetal glucocorticoids may result in growth restriction of the fetus as well as influencing the postnatal adaptation and activity of the pancreas, pituitary-adrenal axis and cardiovascular activity [29]. Postnatally, an adaptive stress response occurs via perceptual cues relating to threat, disruption of expectancies, physical pain, infection or metabolic crisis. Such cues are communicated to the hypothalamus via specific pathways. These signals are integrated in the hypothalamic paraventricular nucleus, where neurons expressing corticotropin-releasing hormone, in collaboration with other peptides such as vasopressin, stimulate the release of adrenocorticotropic hormone $(\mathrm{ACTH})$ from the anterior pituitary gland [30]. When released into circulation, ACTH stimulates the adrenal cortices to synthesize and release cortisol. The link between pituitary ACTH and adrenal cortisol appears to be established some time after week 20 of gestation [28].

In early gestation, the fetal adrenal cortex produces small amounts of cortisol that gradually increase during the third trimester [28]. Across the second trimester, placental $\mathrm{ACTH}$, in combination with other placental hormones, regulates fetal production of adrenal steroids. By the third trimester, the fetal pituitary gland seems to become integrated with the fetal adrenal cortex [28]. By late gestation, the human fetal HPA axis is well developed and functions as a stress-response system in response to stressors such as hypoxia or nutrient restriction. Therefore, external factors that reduce uterine vascular flow may initiate a fetal stress response similar to 
that experienced postnatally [31]. Over the third trimester, HPA activation begins to function according to its well-known negative feedback mechanism, whereby mineralocorticoid and glucocorticoid receptors that are expressed extensively across the hypothalamus and hippocampus operate to inhibit the stress response [30]. However, these two receptors play different roles in modulating both the stress response and the circadian rhythm. (Detailed reviews of the HPA system and its fetal development are available in De Kloet et al. [30]).

The fetal stress response is rapidly transformed postnatally into a circadian rhythm with a peak around the time of waking and a trough during the day that starts to operate within a few weeks of birth for a term baby [32]. The normal circadian rhythm can facilitate termination of the HPA stress response; conversely, disturbances in the daily rhythm may contribute to HPA stress dysregulation [33]. This postnatal interaction between circadian rhythm, stress response and sleep patterns illustrates how a structure-function relationship established in fetal development can also come to function as the platform for more complex developmental systems. Although these have not been so clearly articulated, similar patterns may exist for the development of interpersonal, emotional and behavioral responses across childhood and adolescence [18].

It follows that placental biology has also been closely linked to the fetal programming of stress response. The placenta functions as a temporary endocrine structure that not only regulates the transfer of nutrients to the fetus but also protects it from the growth-inhibiting effects of maternal glucocorticoids [34]. The placenta serves as a critical interface between maternal and fetal physiology, allowing alterations in maternal endocrine, metabolic and immune systems across pregnancy to interact with fetal development. There is an increasing research focus on the role of the placenta as the link between maternal prenatal distress and infant outcomes. Much of this research has focused on an enzyme (11 $\beta$-HSD2) that specifically inactivates glucocorticoids, is highly expressed within the placenta, and has been suggested to play a role in the ontogeny of the fetal HPA-axis $[34,35]$. Placental $11 \beta-H S D 2$ represents a key biomarker of the transmission of maternal stress in pregnancy to the fetus. The placenta may be a central target of maternal pregnancy stress effects and a key mechanistic link between maternal functioning and child mental health outcomes [36].

A number of recent studies are pointing to prenatal maternal stress and depression being key exposures associated with altered epigenetic patterns in both placental tissue and cord blood. These studies provide evidence of alterations in epigenetic programming within specific genes associated with fetal HPA development. Previous studies have used genome-wide DNA methylation scans to examine exposure to psychotropic medications and psychiatric illness in both placenta and cord blood $[37,38]$ and found numerous sites of differential methylation. Alteration in DNA methylation associated with intrauterine exposure to depression has been identified in a number of genes explicitly involved in stress-response systems. For example, Oberlander et al. found elevated methylation of the glucocorticoid receptor gene NR3C1 in cord blood samples from infants born to mothers with depression during the third trimester of pregnancy [39]. In their study, infant HPA reactivity was assessed at three months of age using a measure of information processing designed to induce a mild degree of attention reactivity and, therefore, cognitive stress. Levels of NR3C1 DNA methylation in fetal cord blood predicted the infant's cortisol response to this mildly stressful task.

\section{Major categories of fetal exposure}

The quality of the fetal environment can be compromised in several ways. The first is an indirect pathway where physiological reactions to stress such as endocrine, metabolic or immune responses or toxins like nicotine or alcohol produce vascular restrictions, thereby impeding oxygen and nutrition supply to the fetus. The second pathway is a direct transfer of maternal glucocorticoids or other agents across the placenta. In the late 1990s, Nathanielsz summarized three main classes of prenatal exposure that have been investigated for a range of general health outcomes: lifestyle factors, such as exercise and nutrition; maternal mental health, covering issues of antenatal stress, anxiety and depression; and teratogenic and neurotoxic exposures to specific toxins, such as substance abuse, environmental toxins and prescribed medications [40]. Each class of exposure has also been investigated specifically in terms of child and adolescent mental health outcomes and will be used as a guide for the review of such exposures.

\section{Lifestyle factors}

Lifestyle factors such as exercise and nutrition exert a clear influence on maternal and fetal health across pregnancy and have been central to the investigation of fetal programming - mostly looking at cardiovascular and metabolic outcomes. Barker et al. noted effects on fetal development of maternal diet based on relatively extreme circumstances such as famine [41]. Maternal diet is critical to offspring growth rates and also has a programming effect on metabolic pathways. These mechanisms are thought to impose lifelong risks for the development of both diabetes and obesity [42].

However, recent work suggests that maternal diet may also exert an influence on the biological systems that underpin future vulnerability to mental disorders $[43,44]$. Epidemiological evidence suggests that maternal and infant diet influences the risk for both emotional and behavioral 
disorders in childhood [45]. Jacka et al., for example, reported data from the Mother and Baby study of Norwegian mothers, showing that a higher intake of unhealthy foods during pregnancy predicted behavior problems among children after controlling for a range of confounders. Both maternal nutrition during pregnancy and lactation could be an influence [46].

There is also an emerging body of evidence that maternal obesity during pregnancy is associated with the offspring's subsequent mental health outcomes. Rodrigues et al. found that maternal pre-pregnancy obesity was associated with child inattention symptoms and emotional difficulties [47]. Van Lieshout et al. conducted a systematic review of studies on maternal obesity up until 2011 and found that 8 out of 12 studies showed associations between maternal pregnancy obesity and offspring cognitive problems, attention deficit hyperactivity symptoms, eating disorders in adolescence and psychotic disorders in adulthood [48]. Rodrigues suggested that while maternal adiposity at the time of conception may have a programming effect for child mental health, the possible mechanisms remain obscure [47].

Mechanisms for the impact of lifestyle factors can be considered in terms of maternal mechanisms; placental mechanisms, where vascular and metabolic pathways converge in terms of placental function and would expect to be reflected in intrauterine growth retardation as a common pathway; and fetal mechanisms, such as epigenetic changes or differential fetal brain development in response to blood-borne factors that cross the placenta. Fetal pathways would also include fetal counter-regulatory responses to exposures, such as altered blood glucose or lipid ratios, and activation of hormonal signaling molecules such as leptin. While elucidation of the mechanism involved requires further consideration, there are plausible biological pathways involved and this emerging research strongly suggests that a range of lifestyle factors operating across pregnancy appear to influence the child's subsequent mental health. The relative effects of nutrition, physical activity, obesity and other lifestyle factors are complex and may well interact. However, the evidence appears to be growing that maternal pregnancy and pre-pregnancy lifestyle factors do influence fetal development, and as such would become a modifiable target for prevention intervention.

\section{Maternal depression and stress during pregnancy}

It is well established that children are adversely affected across multiple domains when their mothers' perinatal mental health is untreated or ineffectively treated $[49,50]$. Several lines of evidence suggest that perinatal exposure to maternal depression is associated with dysregulation of the child's HPA response to stress, increasing risk for future stress-related disorders. A wide range of negative child outcomes following maternal depression in the postnatal period have been well documented and these include increased waking cortisol levels during adolescence [51], larger amygdala volume and higher cortisol level at 10 years, higher levels of childhood emotional problems [52], and higher rates of childhood and adolescent depressive symptoms [53]. Infants of depressed mothers show more negative affect and lower sensitivity $[54,55]$ and offspring may experience inadequate physical and verbal stimulation [56].

The global definition of perinatal depression includes both prenatal and postnatal maternal depression and therefore does not allow a clear differential of the effects derived from the intrauterine versus postnatal effects. Around 50\% of women with postnatal depressive symptoms have also experienced depression during their pregnancy $[57,58]$. It is well established that postnatal depression reduces the sensitivity of the mother when interacting with her child and this results in poorer stress regulation and insecure attachments. A meta-analysis of seven studies found that the infants of depressed mothers also showed significantly reduced likelihood of secure attachment and raised likelihood of avoidant and disorganized attachment [59]. Essentially, the putative mechanism here is the negative effects of postnatal maternal caregiving in the context of maternal depression.

However, a fetal programming pathway for the transmission of maternal prenatal depression to offspring outcome is also a likely contributor that has been relatively neglected by developmental researchers. Animal studies have clearly shown that stress experienced by the mother during pregnancy is associated with long-term neurobiological and behavioral effects on her offspring [60]. Studies of prenatal maternal distress in humans show adverse child outcomes, which include symptoms of ADHD [61], lowered cognitive performance and delayed language development [62].

Maternal prenatal stress has an impact on her child's physiological responsiveness to stress. Specifically, recent studies have found that maternal life stressors during pregnancy predict infant cortisol levels and reactive temperament [63-65], and higher resting cortisol throughout the day in adolescence [66]. It would appear that children born to stressed mothers have higher levels of cortisol, which follows from the disruptions to fetal stress biology previously described. Studies of the relationship between prenatal stress and child mental health have been reviewed recently by Glover [67], van den Bergh et al. [68] and Räikkönen et al. [69], so here we refer to only a selection of larger studies.

Maternal prenatal stress in various forms is associated with a number of mental health disorders, but most previous research has been based on disaster records or retrospective assessment of prenatal stress. Khashan et al. [70] used two Danish national registries and found that maternal prenatal exposure to a family bereavement 
during the first trimester was related to a $67 \%$ increased risk of schizophrenia in offspring after adjustment for demographic confounders. Spauwen et al. [71] reported a small increase in risk of psychosis in adolescents whose mothers reported high levels of stress during pregnancy. Kinney et al. used data from the national weather service and found that the prevalence of autism spectrum disorder increased markedly with the severity of a storm or hurricane if it was experienced during late pregnancy [72]. Watson et al. [73] found that maternal prenatal exposure to a severe earthquake in China was associated with an increased risk of depressive symptoms in offspring, and this risk was more than double for male offspring exposed in the second trimester as compared to female offspring.

A number of large cohort studies have examined maternal anxiety and depression in pregnancy to prospectively predict child mental health outcomes. Loomans et al. [74] examined prenatal state anxiety and child outcomes at five years of age in a sample of over 3,000 mothers from the Amsterdam Born Children and their Development study. Maternal state anxiety measured at 16 weeks' gestation was significantly associated with an increased likelihood of inattention or hyperactivity problems for boys (odds ratio $=2.39$ ) but was not significant for girls. Using the Avon Longitudinal Study of Parents and Children, O'Connor et al. [65,75] examined over 7,000 mother-child pairs and found that prenatal maternal anxiety measured at 32 weeks was a significant predictor of inattention or hyperactivity symptoms in boys at 48 and 81 months. However, maternal anxiety measured at 18 weeks' gestation was not a significant predictor of inattention or hyperactivity scores in boys or girls. Drawing on the Mater University of Queensland Study of Pregnancy, Clavarino et al. [76] examined a sample of close to 4,000 mother-child pairs and reported that high prenatal maternal anxiety was associated with an increased risk for attention problems at 5 years that remitted by 14 years (odds ratio $=1.45$ ) and with persistent anxiety problems from 5 to 14 years (odds ratio $=3.02$ ). Robinson et al. [77] studied a sample of 1,700 drawn from the West Australian Raine Study. Women were asked at 18 and 34 weeks' gestation if they had experienced major life stressors and then completed the Child Behavior Checklist when their children were two and five years of age. This study found that a higher number of stressful events was associated with a $23 \%$ increased likelihood of behavioral problems at age two and five and a $15 \%$ increase in the likelihood of emotional problems at age five.

The bulk of the evidence, and current practice in perinatal mental health, is concerned with addressing maternal antenatal depression and anxiety so as to improve the chances of more effective parenting postnatally. However, the findings emerging from fetal programming research suggest that child stress biology is probably being established during the intrauterine period and that preventions should be focused on preconception and pregnancy mental health and stress exposure of mothers.

\section{Prenatal teratogenicity and neurodevelopmental toxicity}

Prenatal teratogenicity originally referred to the risk of alteration in fetal development resulting in structural changes and malformations in offspring from the use of specific agents in the first trimester of pregnancy. This concept has been expanded to refer to a broader range of exposures across pregnancy, and to outcomes beyond malformations that include longer term child developmental and behavioral outcomes [78]. For an agent to be considered a teratogen there must be a specific mechanism by which that agent alters fetal development, and these effects need to occur with particular timing of exposure during pregnancy and show a dose effect in relation to the outcome of interest [79]. Recent work in environmental chemical exposures highlights the need to consider a broader category of neurodevelopmental toxicants. In particular, low-dose exposure to a number of chemicals with endocrine-disrupting properties is related to adverse neurodevelopmental outcomes in a non-dosedependent manner [80]. This departure from classical pharmacological models is predicted from the interplay between a complex and tightly controlled endogenous biological system and an exogenous chemical with biological effects outside of normal physiological boundaries. The elucidation of biological pathways does however remain a fundamental step in establishing a convincing case for causality in observed statistical associations between exposure and outcome.

Prenatal teratogenic exposures have been widely investigated, and well-documented associations with increased risk of emotional, behavioral and cognitive problems include environmental neurotoxicants like lead; substances of abuse such as alcohol, cigarettes and cocaine; and prescribed medications, such as the antiepileptic drug sodium valproate. The evidence for effects from other psychotropic medications is less well established [21,81-84]. Cigarette smoking has been found in up to $11.8 \%$ of pregnant women [85], with $30.3 \%$ of women having some alcohol in pregnancy but only $2.7 \%$ having alcohol across all trimesters [86]. Illicit substance use is likely to be lower, as is exposure to antiepileptic drugs. However, exposure to antidepressant medications was found in as many as $13.4 \%$ of pregnancies in one study from Tennessee in the US [87]. Environmental chemical exposures, by contrast, can be near ubiquitous, underlining the population significance of even subtle neurodevelopmental toxicity. Consider for example that between 1976 and 1980, 77.8\% of the US population had blood lead levels that were more than double the current threshold for reporting [88]. 
There are established associations between exposure to maternal smoking in pregnancy and a range of pregnancy and child health outcomes, from growth restriction and preterm delivery to childhood respiratory illness. Increased incidence of childhood mental illnesses and symptomatology, specifically ADHD and conduct problems, have also been consistently observed [89-93]. Even environmental tobacco exposure (passive smoking) is associated with adverse behavioral outcomes [94-96], although a causal biological pathway has not been established. An association with childhood anxiety and depressive symptoms has been observed [97], but not consistently [93]. A number of recent studies have raised doubts about whether the observed associations between maternal smoking during pregnancy and childhood mental health are fully causal in nature or reflect, in part, shared genetic susceptibility. In the Avon Longitudinal Study, the effects size for paternal smoking was of similar magnitude to that of mothers [98], and in a study of children born following assisted reproduction, the association between maternal smoking in pregnancy and childhood ADHD symptoms was greater in those where the child was genetically related to the mother [99]. Shared inheritance does not, however, appear to account for all of the observed association between ADHD and prenatal tobacco exposure in other cohorts $[91,93,100]$; a recent study from Taiwan explicitly tested and found evidence for a biological pathway that is dependent upon tobacco-related chemicals. Hsieh et al. used genetic studies of children to demonstrate that the association between cord blood cotinine and childhood behavioral difficulties is modified by a genetic polymorphism in the metabolic pathway for smoking-related toxicants [94].

Alcohol has also been associated with a range of teratogenic effects, from fetal alcohol syndrome to a broader fetal alcohol spectrum and later onset developmental and behavioral problems, such as low IQ, specific learning disorders, and internalizing and externalizing symptoms [101,102]. Of the other drugs of abuse, cocaine [103,104], marijuana, benzodiazepines and methamphetamine [105] have each been associated with effects on neurodevelopment and later child mental health outcomes that appear to be independent of social factors $[106,107]$. These effects are subtler than earlier research in the area, and are not apparent until much later in child development and therefore referred as latent or 'sleeper' teratogenic effects [78]. The evidence for opiate exposure is unclear [103]. Epidemiological research in the area is complicated by covariance between substance use and social factors and, in the case of opiates, the small numbers of pregnancies affected and challenges of followup in this relatively chaotic social group.

More recently, longitudinal studies have started to focus on psychotropic medications including antidepressants, antipsychotics and mood stabilizers. Studies from North
America have shown an increasing rate of antidepressant exposure in pregnancy, ranging from $7.6 \%$ to $13.4 \%$ in the US and 5\% in Canada $[87,108,109]$. In Australia, the rate has been shown in data from the Longitudinal Study of Australian Children to be around 2.1\% [110]. The difficulty in examining these agents for potential teratogenic effects is untangling the potential impact of the often serious maternal mental illnesses these agents are used to treat as well as co-morbid exposures that confound outcomes. For instance, one study examining malformation risk and antidepressant exposure found fetal alcohol syndrome was 10 times more likely in children exposed to antidepressants in pregnancy [111].

The most rigorously studied psychotropic class is the antiepileptic drugs, which, in addition to being used in epilepsy, are used as mood stabilizers for treatment of bipolar disorder. These agents have previously been associated with an increased risk of specific structural teratogenicity, such as an increased risk of neural tube defects. There are now a number of rigorous, prospective, longitudinal studies that have followed children from pregnancy to school age to examine for neurodevelopmental and behavioral teratogenic effects [112]. They have identified specific risks with exposure to specific agents and a dose effect. The antipsychotic medications, both typical and atypical, are not associated with a malformation risk but the literature for longer term effects is far too limited to draw any conclusions about child development outcomes [113,114].

There are now a number of large studies of antidepressant exposure in pregnancy and malformation risk but there is still no consensus as to whether there is a small increased risk of birth defects [115]. Studies of longer term teratogenic risks are more limited and most have a small number of participants and short follow-up [116]. However, while no studies to date have found an effect of exposure on global cognition, there are four studies that have found an increased risk of poorer motor development [117-120]. It is important to balance these findings with a number of studies that have found that untreated depression is associated with poorer development, particularly language development [121]. Given the increasing rate of exposure to this class of psychotropic medication, further studies are required that can robustly quantify the potential risks of exposure to balance against the harms of withholding treatments. Such studies ideally require longer follow-up, robust consideration of maternal depression and other confounding factors, and more robust child development measures in order to reach clear conclusions $[87,108,122,123]$.

It can be concluded from studies on psychotropic medication that, to minimize effects on longer term child development, single agents should be considered 
when treating maternal mental illness in pregnancy, keeping doses as low as is feasible for effective treatment. There is an urgent need for further studies to delineate risks for specific agents so that more informed choices can be made [124-126]. When considering the use, and hence exposure, to antidepressants in pregnancy, the issues relevant to child development and mental health outcomes are not just those that relate to exposure per se but also to the impact of untreated maternal mental illness. There is mortality data in both the UK and Australia that suggest mental illness is a leading indirect cause of maternal deaths [127]. In addition, untreated depression potentially impacts on the capacity of women to self-care in pregnancy, particularly in important areas that are increasingly associated with optimal fetal growth and development, such as nutrition and exercise. Finally, clinicians and patients need to consider the effects that remaining depressed may have on a woman's capacity to enjoy motherhood, bond with her baby, and provide responsive and sensitive parenting to the child. All of these aspects of parenting also have a significant impact on short- and long-term child outcomes.

Environmental teratogens and neurodevelopmental toxicants differ from the above by the locus of control of the mother with respect to exposure, but are nevertheless an important modifiable risk factor for preventative mental health strategies. Lead exposure is the prototypic environmental neurotoxicant. Historical exposure was through use of lead in water pipes carrying drinking water, as a fuel additive, and in paints and certain toys. Lead persists in the environment and current household exposure is understood to be primarily from historical soil contamination and old paint, although lead does also continue to be used in a restricted form in hobby activities including soldering, pottery, collectables such as toy soldiers, certain artists' paints, ammunition and fishing sinkers. Large longitudinal studies demonstrate that prenatal [128-130], lifetime $[129,131]$ and current exposure [132-134] are each important [135-137] for neurodevelopmental outcomes. The proposed biological mechanisms have supportive in vitro evidence, including inhibition of N-methyl-D-aspartic acid glutamate receptors (the key molecule regulating synaptic long-term potentiation) and interaction with calcium ion signaling, with much wider implications. Although much research has focused upon outcomes of general cognitive ability and/or ADHD, there is well-replicated evidence for an association between lead exposure and adverse outcomes across broad ranging neurodevelopmental outcomes, including both behavioral and emotional symptomatology [138-141]. The effect size is substantial. Froehlich et al. estimate that in the US, $25.4 \%$ of ADHD in 8- to 15 year-olds is attributable to the low levels of exposure that persist today [142]. Their analysis used data from the
US National Health and Nutrition Examination Survey (NHANES) study, a cross-sectional study but whose design facilitates it having the statistical power to look at clinical outcomes rather than symptomatology.

The evidence base for lead exposure and neurodevelopmental outcomes is not matched anywhere else in the environmental chemical literature. Other environmental chemicals with established neurodevelopmental toxicity include methyl mercury and the polychlorinated biphenyls (PCBs). Environmental exposure to each has established associations with general cognitive function, although the relevance to broader mental health is less clear [143]. Interestingly, the longitudinal data that does exist support an association with prenatal but not postnatal exposure, in support of the DOHaD hypothesis [143]. The strongest evidence is for associations with ADHD and executive function deficits [143]. Wider mental health outcomes have not been adequately studied to draw conclusions, although data would exist in the New Bedford cohort $[144,145]$ that we have not been able to find in publication. Biological mechanisms are also unclear, although PCBs are potent endocrine disruptors and modeling supports thyroid function as a putative mechanism [146].

No consistent specific pattern of deficits emerges that distinguishes neurodevelopmental toxicity due to lead from that due to mercury or PCBs. Observed outcomes in each span both cognitive and affective domains [143], suggesting common developmental pathways of neurodevelopmental toxicity with relevance to mental health. Research to date does imply that cognitive performance and behavioral problems are more strongly associated with environmental toxicity than emotional problems, although it is not clear if this is due to greater sensitivity to neurodevelopmental toxicity, or greater sensitivity in the population-based methodology and assessment tools used to detect subtle effects at the population level.

Exposure to lead and PCBs are on the decline, and methyl mercury exposure appears to be stable [147-150]. Yet there is substantial work still to be done to further reduce exposure to these established neurotoxicants, most notably lead, where the ongoing effects of exposure estimated from the US NHANES data mean that this must remain a key priority in the preventive mental health agenda [142]. At the same time there is a growing body of modern chemicals - not previously evaluated for neurodevelopmental toxicity - that now raise concern as potential neurotoxins in need of further evaluation $[143,151]$. These include manganese and cadmium bivalent heavy metal cations like lead and mercury and many chemicals with endocrine-disrupting actions in vitro similar to those of PCBs (for example, bisphenol A, phthalates, organochloride pesticides, organophosphate pesticides, brominated flame retardants and perfluorinated compounds). The robust evaluation of these chemicals is 
a substantial new opportunity in preventative mental health. However, beyond even this, there is an appreciation that the potential for neurodevelopmental toxicity is unknown for the vast majority of chemicals in ubiquitous modern usage [151], emphasizing that there may be other substantial opportunities for mental health prevention, and that there is a need to prioritize understanding in this area.

Addressing environmental toxins, smoking, alcohol and illicit substance use in pregnancy are important to reduce the implications for child development and mental health outcomes. The latter three also have implications for pregnancy self-care and nutrition. However, there is evidence that both smoking [152] and alcohol use [111] in pregnancy are associated with depression in pregnancy. Therefore, interventions that address a broader approach to a healthy pregnancy may be warranted.

\section{Positive effects of intrauterine exposures}

Whereas most studies focus on negative child developmental outcomes following maternal stress or depression over pregnancy, a number of studies present some positive effects of either stress exposure or prescription of antidepressants. These findings suggest that exposures during pregnancy are complex and need to be carefully considered in terms of the type of exposure, its timing, and potential genetic moderators on child development outcomes where some children may manifest poor outcomes while others may in fact benefit from similar levels of exposure.

For instance, DiPietro et al. reported that increased levels of particularly anxiety and stress - but not depressive symptoms - in pregnancy were associated with higher levels of motor development and mental development in children at two years after adjustments for postnatal confounds [153]. Notably the sample consisted of only healthy women with low-risk pregnancies whose levels of anxiety and depression were not in the clinical range and stressors were minimal. Genetic factors also add to the complexity, with some polymorphisms such as those within SLC6A4 conferring sensitivity to advanced development within positive environments [154]. There is also some evidence that the time of stress exposure within pregnancy may be an important factor in the outcome. By sampling repeatedly across pregnancy, Davis and Sandman showed that exposure to higher levels of cortisol in early pregnancy predicted poorer child development outcomes, whereas higher levels of maternal cortisol in late pregnancy predicted accelerated cognitive development [155]. Such findings suggest that effects of mild stress exposure, possibly towards the later period of gestation, may well confer developmental advantage.

There are now also limited animal and human studies that have shown a beneficial effect on offspring exposed to selective serotonin reuptake inhibitors during early development. One study of rats showed fluoxetine exposure protected rat offspring from the effects of pregnancy stress on adolescent outcomes for both depressive symptoms, as measured by the Forced Swim Test, and increased hippocampal neurogenesis [156]. A second study showed that fluoxetine exposure in rat pups separated from their mothers protected against cell apoptosis of the dentate gyrus of the hippocampus [157]. A study of human neonates showed early speech perception was more advanced in those exposed to selective serotonin reuptake inhibitors than those exposed to controls [158]. Other studies examining global cognitive development in relation to antidepressant exposure and maternal depression have also found a significant effect of maternal depression but not antidepressant exposure on outcomes [159,160]. Given the limited number of studies, these findings must be interpreted with caution but do build a more complex picture of the potential risks and potentially protective aspects of exposure, which also requires consideration of the context in which the exposure to antidepressants occurs.

Findings of positive effects of certain exposure may at first appear confusing or suggest methodological flaws in research. However, some degree of stress is a normal part of life, and increasing levels of glucocorticoids across pregnancy are a normal part of development, serving important maturational functions for the fetus. Given that clinical levels of stress and psychiatric disorders impact on multiple regulatory functions in pregnant women, we can infer that only relatively mild stressors in late pregnancy would be advantageous but further research should investigate this assumption.

\section{Implications for mental health prevention}

There is growing evidence from human studies showing that early exposures to lifestyle factors and maternal mental health are predictive of child behavioral, emotional and learning outcomes. Such exposures appear to alter the developmental trajectory according to subtle programming effects. These effects may impact, for example, on the development of the endocrine response to stress, which can manifest as psychiatric disorder at later points in development, particularly when a child or adolescent is confronted by new challenges. This literature on mental health and lifestyle factors supplements and in many respects expands upon the teratogenic and neurotoxic models of exposure. These exposures have a deleterious impact because they introduce intrauterine conditions which fall outside of biological norms while factors such as maternal stressors or nutrition probably have their impact through inducing different trajectories for development as the fetus attempts to adapt to variation within the intrauterine environment. Factors such as illicit substance exposure, smoking and environmental toxins also have strong evidence of associations with child mental 
disorders. All three areas covered in this review constitute important areas for prevention efforts to target.

Such evidence is now sufficiently compelling that it calls upon researchers to translate such findings into interventions designed to prevent mental disorders. The need for prevention is particularly acute given that mental health treatment systems are coping poorly with demand for mental health services and typically service around $20 \%$ of the population's clinical need [161]. Prevention science and practice has a vital but somewhat neglected role to play in transforming health, education and community service systems to enable the developmental causes of major sources of mental disorder to be effectively targeted. Population and public health models are increasingly being considered as a vehicle for the prevention of high prevalence mental health disorders in childhood, with a focus on attention, emotional and behavioral disorders. It is becoming clearer that risk factors for such common disorders show considerable cross-over with risk factors for major non-communicable diseases [162]. Optimizing health cannot be detached from optimizing mental health [163].

Already a number of successful programs have been developed, such as nurse visitation in the perinatal period [164]. The Nurse-Family Partnership program, originally trialed in New York, has now been replicated in several different populations and shows ongoing child development benefits up to nine years of age [165]. This program comprises home visits by nurses for first-time, disadvantaged mothers across pregnancy and early infancy. The program has three aims: first, to improve pregnancy health and outcomes; second, to improve child health and development; and third, to help parents plan future pregnancies, complete their education and find work [166]. The Nurse-Family Partnership program is associated with a wide range of beneficial outcomes, but of interest to this review is the significant effect on child outcomes, including educational improvement, as compared to control children [165].

A recent Cochrane review reported emerging evidence to show that current interventions aiming to prevent postnatal depression in women are of benefit [167]. Notably, few of these interventions also examine outcomes for children. There is considerable scope for the development of effective interventions for pregnant women to address not only depression but equally anxiety disorders and high stress exposures $[168,169]$. Overall, the quality of evidence for existing prevention programs in the preconception, pregnancy and early infancy period is limited, and often target only one of the many deleterious factors that impact on child development.

The ultimate goal of prevention in a mental health context refers to measurably reducing the population rates of mental health disorders by using strategic efforts to address their known causes. Since it often adopts a population perspective, prevention science tends to remain at some distance from research on the neurobiological systems implicated in early development. However, prevention efforts could effectively target immature, developing neurobiological systems. Early experience research is highly applicable to prevention as it suggests ways that not only adverse postnatal experiences but also preconception and intrauterine factors might constitute targets for prevention efforts.

The current review has identified strong evidence for the deleterious impact of maternal mental health and a range of teratogenic and neurotoxic factors. There is also emerging evidence for lifestyle factors such as diet and obesity. Further robust evaluation of psychological and chemical exposures that cross the placenta or impede placental function via compromised maternal health and mental health will continue to create substantial new opportunities in preventative mental health. The general implication of the $\mathrm{DOHaD}$ model is that the prevention of compromised fetal development would potentially have long-term health and mental health benefits for offspring.

We have focused on three major classes of pregnancy exposure - not to suggest that these are exhaustive but to provide a framework to guide consideration of intervention efforts. As Schlotz et al. note, an interesting feature of the fetal programming research is that the diverse range of exposures reviewed - such as prenatal smoking, stressful events and depression - show broadly speaking similar patterns of outcomes in terms of child behavioral, emotional and attention deficits [21]. This suggests placental transmission or compromised placental function may comprise a small number of mechanisms that interrupt fetal development and therefore result in a similar set of child outcomes. It also shows the commonality between mental health and other health outcomes. Fetal growth, therefore, could continue to be considered a useful index of fetal adversity but also as an outcome for prenatal and preconception intervention to target, particularly for population-level interventions.

Pregnancy care provides a convenient opportunity for health interventions given the high level of engagement with the health delivery system, and this is a key time point to target public health strategies around psychological and physical preparation for pregnancy, smoking, alcohol, diet, and exposure to known teratogen and neurodevelopmental toxins. However, given that $40 \%$ or more of pregnancies are unplanned, and given the importance of the preconception period for many factors we have identified here, a broader approach is needed. Effective strategies would therefore be anticipated to combine targeted interventions within pregnancy care, with broader interventions that will reach all women of child-bearing age, or that are effectively 
population-wide, following the successful model of folate supplementation for prevention of neural tube defects. This is especially relevant for developing strategies towards reducing environmental exposure to chemicals with neurodevelopmental toxicity.

Interventions that recognize and support the formation of a family unit are important to consider as an alternative to focusing intervention only on maternal care. Partner support has consistently been found to be a major predictor of maternal coping with stress and perinatal depression. Policies and practices to support pregnant women in the general population and also efforts to support women at elevated risk are of particular importance. In perinatal psychiatry, the development of antidepressants that do not cross the placenta and therefore do not impact on fetal development are currently in the development phase and, if effective, $t$ could have a significant impact on reducing antenatal maternal depression and anxiety.

Recommendations arising from the current review are threefold. First, to develop recommendations on pregnancy health based on the current evidence base on exposures relevant to optimizing the mental health of offspring. Such recommendations need to be examined in relation to other preventative measures aimed at improving general pregnancy health so as to capitalize on the commonality of risk factors for both child health and mental health outcomes. Second, health promotion programs targeted to both the public and health professionals to encourage full implementation of such recommendations. Third, targeted intervention to high-risk groups, which might take the form of behavior and education programs for young adult women of child-bearing age in high risk groups concerning pregnancy health and infant development. High risk groups include women who in preconception or during pregnancy experiencing major (mental) health difficulties or other disadvantages, major stressors or other adversities, and mothers of infants who are premature, of multiple birth, or have birth complications, low birth weight or failure to thrive.

\section{Abbreviations}

11ß-HSD2: type 2 isoform of 11 beta-hydroxysteroid dehydrogenase; ACTH: adrenocorticotrophic hormone; ADHD: attention deficit hyperactivity disorder; DOHaD: Developmental origins of health and disease; HPA: hypothalamic-pituitary-adrenal; NHANES: National Health and Nutrition Examination Survey; PCBs: polychlorinated biphenyls.

\section{Competing interests}

The authors declare that they have no competing interests.

\section{Authors' contributions}

AJL designed the review and drafted the manuscript. MG co-designed the review and conducted a review of psychotropic exposures. TG conduced a review of stress and depression exposures. CS reviewed teratogenic and neurotoxic exposures. All authors developed conclusions and recommendations based on the areas reviewed and helped to draft the manuscript. All authors read and approved the final manuscript.

\section{Acknowledgements}

We thank the Alliance for the Prevention of Mental Disorders, Felice Jacka, Tony Jorm, John Toumbourou and Michael Berk for their support of the Alliance and Rotary Health, Australia for sponsorship of the Canberra Symposium on the Prevention of Mental Disorders where some of these ideas were originally presented. We thank the Centre for Mental Health and Well-Being at Deakin University, the Mercy Hospital for Women and beyondblue for their support of our research into Early Programming.

The work of CS on this manuscript was supported by a postgraduate scholarship from the National Health and Medical Research Council of Australia.

\section{Author details}

'School of Psychology, Faculty of Health, Deakin University, Melbourne, Australia. ${ }^{2}$ Department of Perinatal Mental Health, Mercy Hospital for Women, Melbourne, Australia. ${ }^{3}$ Murdoch Childrens Research Institute, Melbourne, Australia.

Received: 9 October 2013 Accepted: 21 January 2014

Published: 24 February 2014

\section{References}

1. Barker DJ: The developmental origins of chronic adult disease. Acta Paediatrica 2004, 93:26-33.

2. Belfer ML: Child and adolescent mental disorders: the magnitude of the problem across the globe. J Child Psychol Psychiatry 2008, 49:226-236.

3. Ravens-Sieberer $\mathrm{U}$, Wille N, Erhart M, Bettge $\mathrm{S}$, Wittchen HU, Rothenberger A, Herpertz-Dahlmann B, Resch F, Holling H, Bullinger M, Barkmann C, Schulte-Markwort M, Dopfner M, BELLA study group: Prevalence of mental health problems among children and adolescents in Germany: results of the BELLA study within the National Health Interview and Examination Survey. Eur Child Adolesc Psychiatry 2008, 17:22-33.

4. Sawyer MG, Arney FM, Baghurst PA, Clarke JJ, Graetz BW, Kosky RJ, Nurcomber B, Patton GC, Prior MR, Raphael B, et al: The mental health of young people in Australia-key findings from the child and adolescent component of the national survey of mental health and well-being. Aust N Z J Psychiatry 2001, 35:806-814.

5. Merikangas KR, He JP, Brody D, Fisher PW, Bourdon K, Koretz DS: Prevalence and treatment of mental disorders among US children in the 2001-2004 NHANES. Pediatrics 2010, 125:75-81.

6. Meltzer H: Childhood mental disorders in Great Britain: an epidemiological perspective. Child Care Pract 2007, 13:313-326.

7. Rescorla L, Achenbach TM, Ivanova MY, Dumenci L, Almqvist F, Bilenberg N, Bird H, Broberg A, Dobrean A, Dopfner M, et al: Epidemiological comparisons of problems and positive qualities reported by adolescents in 24 countries. J Consult Clin Psychol 2007, 75:351-358.

8. Angold A, Costello EJ, Worthman CM: Puberty and depression- the roles of age, pubertal status and pubertal timing. Psychol Med 1998, 28:51-61.

9. Mueller BR, Bale TL: Sex-specific programming of offspring emotionality after stress early in pregnancy. J Neurosci 2008, 28:9055-9065.

10. Barker DJ: The Wellcome Foundation Lecture, 1994. The fetal origins of adult disease. Proc Biol Sci 1995, 262:37-43.

11. Gluckman PD, Hanson MA: The developmental origins of health and disease: the breadth and importance of the concept. In Early Life Origins of Health and Disease. Edited by Wintour EM, Owens JA. New York, NY: Springer Science + Business Media; 2006.

12. Kieling C, Baker-Henningham $\mathrm{H}$, Belfer $\mathrm{M}$, Conti $\mathrm{G}$, Ertem I, Omigbodun O, Rohde LA, Srinath S, Ulkuer N, Rahman A: Child and adolescent mental health worldwide: evidence for action. Lancet 2011, 378:1515-1525.

13. Stearns SC, Koella JC: The evolution of phenotypic plasticity in life-history traits: predictions of reaction norms for age and size at maturity. Evolution 1986, 40:893-913.

14. Gluckman PD, Hanson MA, Beedle AS: Early life events and their consequences for later disease: a life history and evolutionary perspective. Am J Hum Biol 2007, 19:1-19.

15. West-Eberhard MJ: Developmental Plasticity and Evolution. Oxford: Oxford University Press; 2003.

16. Gluckman PD, Hanson MA, Bateson P, Beedle AS, Law CM, Bhutta ZA, Anokhin KV, Bougnères P, Chandak GR, Dasgupta $P$, et al: Towards a new developmental synthesis: adaptive developmental plasticity and human disease. Lancet 2009, 373:1654-1657. 
17. Bateson P, Barker D, Clutton-Brock T, Deb D, D'Udine B, Foley R, Gluckman P, Godfrey K, Kirkwood T, Lahr M: Developmental plasticity and human health. Nature 2004, 430:419-421

18. Gluckman PD, Hanson MA: The conceptual basis for the developmental origins of health and disease. In Developmental Origins of Health and Disease. Edited by Gluckman PD, Hanson MA. New York: Cambridge University Press; 2006:33-50.

19. Ollikainen M, Smith KR, Joo EJ-H, Ng HK, Andronikos R, Novakovic B, Aziz NKA, Carlin JB, Morley R, Saffery R: DNA methylation analysis of multiple tissues from newborn twins reveals both genetic and intrauterine components to variation in the human neonatal epigenome. Hum Mol Genet 2010, 19:4176-4188.

20. Meaney MJ, Szyf M, Seckl JR: Epigenetic mechanisms of perinatal programming of hypothalamic-pituitary-adrenal function and health. Trends Mol Med 2007, 13:269-277.

21. Schlotz W, Phillips DI: Fetal origins of mental health: evidence and mechanisms. Brain Behav Immun 2009, 23:905-916.

22. Whitelaw E, Garrick D: Epigenetic mechanisms. In Developmental Origins of Health and Disease. Edited by Gluckman PD, Hanson MA. New York: Cambridge University Press; 2006:62-74.

23. Martino D, Loke YJ, Gordon L, Ollikainen M, Cruickshank MN, Saffery R, Craig JM: Longitudinal, genome-scale analysis of DNA methylation in twins from birth to 18 months of age reveals rapid epigenetic change in early life and pair-specific effects of discordance. Genome Bio/ 2013, 14:R42.

24. Barker DJ, Osmond C, Rodin I, Fall C, Winter P: Low weight gain in infancy and suicide in adult life. BMJ 1995, 311:1203.

25. Talge NM, Neal C, Glover V: Antenatal maternal stress and long-term effects on child neurodevelopment: how and why? J Child Psychol Psychiatry 2007, 48:245-261.

26. Swanson JD, Wadhwa PM: Developmental origins of child mental health disorders. J Child Psychol Psychiatry 2008, 49:1009-1019.

27. Lupien SJ, McEwen BS, Gunnar MR, Heim C: Effects of stress throughout the lifespan on the brain, behaviour and cognition. Nat Rev Neurosci 2009, 10:434-445.

28. Bolt $R$, Van Weissenbruch M, Lafeber $H$, Delemarre-Van de Waal H: Development of the hypothalamic-pituitary-adrenal axis in the fetus and preterm infant. J Pediatr Endocrinol Metab 2002, 15:759-770.

29. Challis J, Sloboda D, Matthews S, Holloway A, Alfaidy N, Patel F, Whittle W, Fraser M, Moss T, Newnham J: The fetal placental hypothalamic-pituitaryadrenal (HPA) axis, parturition and post natal health. Mol Cell Endocrinol 2001, 185:135-144.

30. De Kloet ER, Joëls M, Holsboer F: Stress and the brain: from adaptation to disease. Nat Rev Neurosci 2005, 6:463-475

31. Phillips DI, Jones A: Fetal programming of autonomic and HPA function: do people who were small babies have enhanced stress responses? J Physiol 2006, 572:45-50

32. Price $D$, Close $G$, Fielding B: Age of appearance of circadian rhythm in salivary cortisol values in infancy. Arch Dis Child 1983, 58:454-456.

33. Gunnar M, Quevedo K: The neurobiology of stress and development. Annu Rev Psychol 2007, 58:145-173.

34. Cottrell EC, Seckl JR: Prenatal stress, glucocorticoids and the programming of adult disease. Front Behav Neurosci 2009, 3:1-9.

35. O'donnell K, O'connor T, Glover V: Prenatal stress and neurodevelopment of the child: focus on the HPA axis and role of the placenta. Dev Neurosci 2009, 31:285-292.

36. Monk C, Spicer J, Champagne FA: Linking prenatal maternal adversity to developmental outcomes in infants: the role of epigenetic pathways. Dev Psychopathol 2012, 24:1361-1376.

37. Schroeder JW, Smith AK, Brennan PA, Conneely KN, Kilaru V, Knight BT, Newport DJ, Cubells JF, Stowe ZN: DNA methylation in neonates born to women receiving psychiatric care. Epigenetics 2012, 7:409-414

38. Smith AK, Conneely KN, Newport DJ, Kilaru V, Schroeder JW, Pennell PB, Knight BT, Cubells JC, Stowe ZN, Brennan PA: Prenatal antiepileptic exposure associates with neonatal DNA methylation differences. Epigenetics 2012, 7:458-463.

39. Oberlander TF, Weinberg J, Papsdorf M, Grunau R, Misri S, Devlin AM: Prenatal exposure to maternal depression, neonatal methylation of human glucocorticoid receptor gene (NR3C1) and infant cortisol stress responses. Epigenetics 2008, 3:97-106.

40. Nathanielsz PW, Nathanielsz P: Life in the Womb: The Origin of Health and Disease. Ithaca, NY: Promethean Press; 1999.
41. Barker DJ: Maternal nutrition, fetal nutrition, and disease in later life. Nutrition 1997, 13:807-813.

42. Bale TL, Baram TZ, Brown AS, Goldstein JM, Insel TR, McCarthy MM, Nemeroff CB, Reyes TM, Simerly RB, Susser ES: Early life programming and neurodevelopmental disorders. Biol Psychiatry 2010, 68:314-319.

43. Sullivan EL, Grayson B, Takahashi D, Robertson N, Maier A, Bethea CL, Smith MS, Coleman K, Grove KL: Chronic consumption of a high-fat diet during pregnancy causes perturbations in the serotonergic system and increased anxiety-like behavior in nonhuman primate offspring. J Neurosci 2010, 30:3826-3830.

44. Vucetic Z, Kimmel J, Totoki K, Hollenbeck E, Reyes TM: Maternal high-fat diet alters methylation and gene expression of dopamine and opioid-related genes. Endocrinology 2010, 151:4756-4764.

45. Jacka FN, Ystrom E, Brantsaeter AL, Karevold E, Roth C, Haugen M, Meltzer HM, Schjolberg S, Berk M: Maternal and early postnatal nutrition and mental health of offspring by age 5 years: a prospective cohort study. J Am Acad Child Adolesc Psychiatr 2013, 52:1038-1047.

46. Keenan K, Bartlett TQ, Nijland M, Rodriguez JS, Nathanielsz PW, Zürcher NR Poor nutrition during pregnancy and lactation negatively affects neurodevelopment of the offspring: evidence from a translational primate model. Am J Clin Nutr 2013, 98:396-402.

47. Rodriguez A: Maternal pre-pregnancy obesity and risk for inattention and negative emotionality in children. J Child Psychol Psychiatry 2010, 51:134-143.

48. Van Lieshout RJ, Taylor VH, Boyle MH: Pre-pregnancy and pregnancy obesity and neurodevelopmental outcomes in offspring: a systematic review. Obes Rev 2011, 12:e548-e559.

49. Goodman SH, Gotlib IH: Risk for psychopathology in the children of depressed mothers: a developmental model for understanding mechanisms of transmission. Psychol Rev 1999, 106:458-490.

50. Grote NK, Bridge JA, Gavin AR, Melville JL, lyengar S, Katon WJ: A meta-analysis of depression during pregnancy and the risk of preterm birth, low birth weight, and intrauterine growth restriction. Arch Gen Psychiatry 2010, 67:1012.

51. Murray L, Halligan SL, Goodyer I, Herbert J: Disturbances in early parenting of depressed mothers and cortisol secretion in offspring: a preliminary study. J Affect Disord 2010, 122:218-223.

52. Bagner DM, Pettit JW, Lewinsohn PM, Seeley JR: Effect of maternal depression on child behavior: a sensitive period? J Am Acad Child Adolesc Psychiatry 2010, 49:699-707.

53. Bureau JF, Easterbrooks MA, Lyons-Ruth K: Maternal depressive symptoms in infancy: unique contribution to children's depressive symptoms in childhood and adolescence? Dev Psychopathol 2009, 21:519-537.

54. Dawson G, Klinger LG, Panagiotides H, Hill D, Spieker S: Frontal lobe activity and affective behavior of infants of mothers with depressive symptoms. Child Dev 1992, 63:725-737.

55. Tronick EZ: Emotions and emotional communication in infants. Am Psychol 1989, 44:112-119.

56. Field T: Maternal depression effects on infants and early interventions. Prev Med 1998, 27:200-203.

57. Gotlib IH, Whiffen VE, Mount JH, Milne K, Cordy NI: Prevalence rates and demographic characteristics associated with depression in pregnancy and the postpartum. J Consult Clin Psychol 1989, 57:269-274.

58. O'Hara MW, Swain AM: Rates and risk of postpartum degression - a meta-analysis. Int Rev Psychiatry 1996, 8:37-54

59. Martins C, Gaffan EA: Effects of early maternal depression on patterns of infant-mother attachment: a meta-analytic investigation. J Child Psychol Psychiatry 2000, 41:737-746.

60. Weinstock M: The potential influence of maternal stress hormones on development and mental health of the offspring. Brain Behav Immun 2005, 19:296-308.

61. Van den Bergh BRH, Marcoen A: High antenatal maternal anxiety is related to ADHD symptoms, externalizing problems, and anxiety in 8- and 9-year-olds. Child Dev 2004, 75:1085-1097.

62. Bergman K, Sarkar P, Glover V, O'Connor TG: Maternal prenatal cortisol and infant cognitive development: moderation by infant-mother attachment. Biol Psychiatry 2010, 67:1026-1032.

63. Lewis AJ, Olsson CA: Early life stress and child temperament style as predictors of childhood anxiety and depressive symptoms: findings from the longitudinal study of Australian children. Depress Res Treat 2011, 2012:1-9.

64. Kaplan LA, Evans L, Monk C: Effects of mothers' prenatal psychiatric status and postnatal caregiving on infant biobehavioral regulation: can prenatal programming be modified? Early Hum Dev 2008, 84:249-256. 
65. O'Connor TG, Heron J, Golding J, Beveridge M, Glover V: Maternal antenatal anxiety and children's behavioural/emotional problems at 4 years: report from the Avon Longitudinal Study of Parents and Children. Br J Psychiatry 2002, 180:502-508.

66. Van den Bergh BRH, van Calster B, Smits T, van Huffel S, Lagae L: Antenatal maternal anxiety is related to HPA-axis dysregulation and self-reported depressive symptoms in adolescence: a prospective study on the fetal origins of depressed mood. Neuropsychopharmacology 2008, 33:536-545.

67. Glover $V$ : Annual research review: prenatal stress and the origins of psychopathology: an evolutionary perspective. J Child Psychol Psychiatry 2011, 52:356-367.

68. Van den Bergh BR, Mulder EJ, Mennes M, Glover V: Antenatal maternal anxiety and stress and the neurobehavioural development of the fetus and child: links and possible mechanisms. A review. Neurosci Biobehav Rev 2005, 29:237-258.

69. Räikkönen K, Seckl J, Pesonen A-K, Simons A, Van den Bergh B: Stress, glucocorticoids and liquorice in human pregnancy: programmers of the offspring brain. Stress 2011, 14:590-603.

70. Khashan AS, Abel KM, McNamee R, Pedersen MG, Webb RT, Baker PN, Kenny LC, Mortensen PB: Higher risk of offspring schizophrenia following antenatal maternal exposure to severe adverse life events. Arch Gen Psychiatry 2008, 65:146-152.

71. Spauwen J, Krabbendam L, Lieb R, Wittchen HU, van Os J: Early maternal stress and health behaviours and offspring expression of psychosis in adolescence. Acta Psychiatr Scand 2004, 110:356-364

72. Kinney DK, Miller AM, Crowley DJ, Huang E, Gerber E: Autism prevalence following prenatal exposure to hurricanes and tropical storms in Louisiana. J Autism Dev Disord 2008, 38:481-488.

73. Watson JB, Mednick SA, Huttunen M, Wang X: Prenatal teratogens and the development of adult mental illness. Dev Psychopathol 1999, 11:457-466.

74. Loomans EM, van der Stelt O, van Eijsden M, Gemke RJBJ, Vrijkotte T, van den Bergh BR: Antenatal maternal anxiety is associated with problem behaviour at age five. Early Hum Dev 2011, 87:565-570.

75. O'Connor TG, Heron J, Golding J, Glover V, the ALSPAC Study Team: Maternal antenatal anxiety and behavioural/ emotional problems in children: a test of a programming hypothesis. J Child Psychol Psychiatry 2003, 44:1025-1036.

76. Clavarino AM, Mamun AA, O'Callaghan M, Aird R, Bor W, O'Callaghan F, Williams GM, Marrington S, Najman JM, Alati R: Maternal anxiety and attention problems in children at 5 and 14 years. J Atten Disord 2010, 13:658-667.

77. Robinson M, Oddy WH, Li J, Kendall GE, de Klerk NH, Silburn SR, Zubrick SR Newnham JP, Stanley FJ, Mattes E: Pre- and postnatal influences on preschool mental health: a large-scale cohort study. J Child Psychol Psychiatry 2008, 49:1118-1128.

78. Mayes LC, Ward A: Principles of neurobehavioral teratology. Neurodevelopmental Mech Psychopathol 2003:3-33.

79. Obican S, Scialli AR: Teratogenic exposures. Am J Med Genet C Semin Med Genet 2011, 157C:150-169.

80. Vandenberg LN, Colborn T, Hayes TB, Heindel JJ, Jacobs DR, Lee D-H, Shioda T, Soto AM, vom Saal FS, Welshons W: Hormones and endocrine-disrupting chemicals: low-dose effects and nonmonotonic dose responses. Endocr Rev 2012, 33:378-455.

81. Lewis MW, Misra S, Johnson HL, Rosen TS: Neurological and developmental outcomes of prenatally cocaine-exposed offspring from 12 to 36 months. Am J Drug Alcohol Abuse 2004, 30:299-320.

82. McDonald SD, Walker M, Perkins SL, Beyene J, Murphy K, Gibb W, Ohlsson A: The effect of tobacco exposure on the fetal hypothalamic-pituitary-adrenal axis. Bjog 2006, 113:1289-1295.

83. Stene-Larsen $\mathrm{K}$, Borge AlH, Vollrath ME: Maternal smoking in pregnancy and externalizing behavior in 18-month-old children: results from a populationbased prospective study. J Am Acad Child Adolesc Psychiatr 2009, 48:283-289.

84. Lester BM, Bagner DM, Liu J, LaGasse LL, Seifer R, Bauer CR, Shankaran S, Bada H, Higgins RD, Das A: Infant neurobehavioral dysregulation: behavior problems in children with prenatal substance exposure. Pediatrics 2009, 124:1355-1362.

85. Ebrahim SH, Floyd RL, Merritt RK II, Decoufle P, Holtzman D: Trends in pregnancy-related smoking rates in the United States, 1987-1996. JAMA 2000, 283:361-366.

86. Ethen MK, Ramadhani TA, Scheuerle AE, Canfield MA, Wyszynski DF, Druschel CM, Romitti PA: Alcohol consumption by women before and during pregnancy. Matern Child Health J 2009, 13:274-285.
87. Cooper WO, Willy ME, Pont SJ, Ray WA: Increasing use of antidepressants in pregnancy. Am J Obstet Gynecol 2007, 196:544.

88. Pirkle JL, Brody DJ, Gunter EW, Kramer RA, Paschal DC, Flegal KM, Matte TD: The decline in blood lead levels in the United States. JAMA 1994, 272:284-291.

89. Linnet KM, Dalsgaard S, Obel C, Wisborg K, Henriksen TB, Rodriguez A, Kotimaa A, Moilanen I, Thomsen PH, Olsen J, Jarvelin MR: Maternal lifestyle factors in pregnancy risk of ADHD. Am J Psychiatr 2003, 160:1028-1040.

90. Rodriguez A, Bohlin G: Are maternal smoking and stress during pregnancy related to ADHD symptoms in children? J Child Psychol Psychiatry 2005, 46:246-254.

91. Tiesler CM, Chen CM, Sausenthaler S, Herbarth O, Lehmann I, Schaaf B, Kramer U, von Berg A, von Kries R, Wichmann HE, Heinrich J: Passive smoking and behavioural problems in children: results from the LISAplus prospective birth cohort study. Environ Res 2011, 111:1173-1179.

92. Braun JM, Kahn RS, Froehlich T, Auinger P, Lanphear BP: Exposures to environmental toxicants and attention deficit hyperactivity disorder in U.S. children. Environ Health Perspect 2006, 114:1904-1909.

93. Brion MJ, Victora C, Matijasevich A, Horta B, Anselmi L, Steer C, Menezes AM, Lawlor DA, Davey Smith G: Maternal smoking and child psychological problems: disentangling causal and noncausal effects. Pediatrics 2010, 126:e57-e65.

94. Hsieh CJ, Jeng SF, Su YN, Liao HF, Hsieh WS, Wu KY, Chen PC: CYP1A1 modifies the effect of maternal exposure to environmental tobacco smoke on child behavior. Nicotine Tob Res 2010, 12:1108-1117.

95. Liu J, Leung PW, McCauley L, Ai Y, Pinto-Martin J: Mother's environmental tobacco smoke exposure during pregnancy and externalizing behavior problems in children. Neurotoxicology 2013, 34:167-174.

96. Twardella D, Bolte G, Fromme H, Wildner M, von Kries R: Exposure to secondhand tobacco smoke and child behaviour - results from a cross-sectional study among preschool children in Bavaria. Acta Paediat 2010, 99:106-111.

97. Ruckinger S, Rzehak P, Chen CM, Sausenthaler S, Koletzko S, Bauer CP, Hoffmann U, Kramer U, Berdel D, von Berg A, et al: Prenatal and postnatal tobacco exposure and behavioral problems in 10-year-old children: results from the GINI-plus prospective birth cohort study. Environ Health Perspect 2010, 118:150-154

98. Langley K, Heron J, Smith GD, Thapar A: Maternal and paternal smoking during pregnancy and risk of ADHD symptoms in offspring: testing for intrauterine effects. Am J Epidemiol 2012, 176:261-268.

99. Thapar A, Rice F, Hay D, Boivin J, Langley K, van den Bree M, Rutter M, Harold G: Prenatal smoking might not cause attention-deficit/hyperactivity disorder: evidence from a novel design. Biol Psychiatry 2009, 66:722-727.

100. Buschgens CJ, Swinkels SH, van Aken MA, Ormel J, Verhulst FC, Buitelaar JK: Externalizing behaviors in preadolescents: familial risk to externalizing behaviors, prenatal and perinatal risks, and their interactions. Eur Child Adolesc Psychiatry 2009, 18:65-74.

101. Streissguth AP, Barr HM, Sampson PD: Moderate prenatal alcohol exposure: effects on child IQ and learning problems at age $71 / 2$ years. Alcohol Clin Exp Res 1990, 14:662-669.

102. Sood B, Delaney-Black V, Covington C, Nordstrom-Klee B, Ager J, Templin T, Janisse J, Martier S, Sokol RJ: Prenatal alcohol exposure and childhood behavior at age 6 to 7 years: I. dose-response effect. Pediatrics 2001, 108:e34-e34.

103. Bada HS, Das A, Bauer CR, Shankaran S, Lester B, LaGasse L, Hammond J, Wright LL, Higgins R: Impact of prenatal cocaine exposure on child behavior problems through school age. Pediatrics 2007, 119:e348-e359.

104. Savage J, Brodsky NL, Malmud E, Giannetta JM, Hurt H: Attentional functioning and impulse control in cocaine-exposed and control children at age ten years. J Dev Behav Pediatr 2005, 26:42-47.

105. LaGasse LL, Derauf C, Smith LM, Newman E, Shah R, Neal C, Arria A, Huestis MA, DellaGrotta S, Lin H, Danereau L, Lester BM: Prenatal methamphetamine exposure and childhood behavior problems at 3 and 5 years of age. Pediatrics 2012, 129:681-688.

106. Goldschmidt L, Day NL, Richardson GA: Effects of prenatal marijuana exposure on child behavior problems at age 10. Neurotoxicol Teratol 2000, 22:325-336.

107. Day NL, Leech SL, Goldschmidt L: The effects of prenatal marijuana exposure on delinquent behaviors are mediated by measures of neurocognitive functioning. Neurotoxicol Teratol 2011, 33:129-136.

108. Andrade SE, Raebel MA, Brown J, Lane K, Livingston J, Boudreau D, Rolnick SJ, Roblin D, Smith DH, Willy ME, Staffa JA, Platt R: Use of antidepressant medications during pregnancy: a multisite study. Am J Obstet Gynecol 2008, 198:194. e191-195. 
109. Oberlander TF, Warburton W, Misri S, Aghajanian J, Hertzman C: Neonatal outcomes after prenatal exposure to selective serotonin reuptake inhibitor antidepressants and maternal depression using population-based linked health data. Arch Gen Psychiatry 2006, 63:898-906.

110. Lewis AJ, Bailey C, Galbally M: Anti-depressant use during pregnancy in Australia: findings from the Longitudinal Study of Australian Children. Aust N Z J Public Health 2012, 36:487-488.

111. Malm H, Artama M, Gissler M, Ritvanen A: Selective serotonin reuptake inhibitors and risk for major congenital anomalies. Obstet Gynecol 2011, 118:111.

112. Galbally M, Roberts M, Buist A: Mood stabilizers in pregnancy: a systematic review. Aust N Z J Psychiatry 2010, 44:967-977.

113. Einarson A, Boskovic R: Use and safety of antipsychotic drugs during pregnancy. J Psychiatr Pract 2009, 15:183-192.

114. Einarson A, Einarson TR: Maternal use of antipsychotics in early pregnancy: little evidence of increased risk of congenital malformations. Evid Based Ment Health 2009, 12:29.

115. Gentile S: Selective serotonin reuptake inhibitor exposure during early pregnancy and the risk of birth defects. Acta Psychiatr Scand 2011, 123:266-275.

116. Gentile S, Galbally M: Prenatal exposure to antidepressant medications and neurodevelopmental outcomes: a systematic review. J Affect Disord 2010, 128:1-9.

117. Casper RC, Fleisher BE, Lee-Ancajas JC, Gilles A, Gaylor E, DeBattista A, Hoyme HE: Follow-up of children of depressed mothers exposed or not exposed to antidepressant drugs during pregnancy. J Pediatr 2003, 142:402-408.

118. Casper RC, Gilles AA, Fleisher BE, Baran J, Enns G, Lazzeroni LC: Length of prenatal exposure to selective serotonin reuptake inhibitor (SSRI) antidepressants: effects on neonatal adaptation and psychomotor development. Psychopharmacology (Berl) 2011, 217:211-219.

119. Galbally M, Lewis AJ, Buist A: Developmental outcomes of children exposed to antidepressants in pregnancy. Aust N Z J Psychiatry 2011, 45:393-399.

120. Mortensen J, Olsen J, Larsen H, Bendsen J, Obel C, Sørensen H: Psychomotor development in children exposed in utero to benzodiazepines, antidepressants, neuroleptics, and anti-epileptics. Eur J Epidemiol 2003, 18:769-771.

121. Weikum WM, Oberlander TF, Hensch TK, Werker JF: Prenatal exposure to antidepressants and depressed maternal mood alter trajectory of infant speech perception. Proc Natl Acad Sci 2012, 109:17221-17227.

122. Lewis A, Galbally M, Bailey C: Perinatal mental health, antidepressants and neonatal outcomes: findings from the Longitudinal Study of Australian Children. Neonatal Paediatr Child Health Nurs 2012, 15:22-28.

123. Galbally M, Snellen M, Lewis AJ: A review of the use of psychotropic medication in pregnancy. Current Opinion in Obstetrics and Gynecology 2011, 23:408-414.

124. Lewis AJ, Galbally M, Opie G, Buist A: Neonatal growth outcomes at birth and one month postpartum following in utero exposure to antidepressant medication. Aust N Z J Psychiatry 2010, 44:482-487.

125. Galbally M, Lewis AJ, Lum J, Buist A: Serotonin discontinuation syndrome following in utero exposure to antidepressant medication: prospective controlled study. Aust N Z J Psychiatry 2009, 43:846-854.

126. Galbally M, Snellen M, Lewis AJ: A review of the use of psychotropic medication in pregnancy. Curr Opin Obstet Gynecol 2011. Publish Ahead of Print:10.1097/GCO.1090b1013e32834b32892f32833.

127. Austin MP, Kildea S, Sullivan E: Maternal mortality and psychiatric morbidity in the perinatal period: challenges and opportunities for prevention in the Australian setting. Med J Aust 2007, 186:364-367.

128. Schnaas L, Rothenberg SJ, Flores M-F, Martinez S, Hernandez C, Osorio E, Velasco SR, Perroni E: Reduced intellectual development in children with prenatal lead exposure. Environ Health Perspect 2005, 114:791-797.

129. Wasserman GA, Staghezza-Jaramillo B, Shrout P, Popovac D, Graziano J: The effect of lead exposure on behavior problems in preschool children. Am J Public Health 1998, 88:481-486.

130. Dietrich KN, Ris MD, Succop PA, Berger OG, Bornschein RL: Early exposure to lead and juvenile delinquency. Neurotoxicol Teratol 2001, 23:511-518.

131. Tong S, Baghurst PA, Sawyer MG, Burns J, McMichael AJ: Declining blood lead levels and changes in cognitive function during childhood: the Port Pirie Cohort Study. JAMA 1998, 280:1915-1919.

132. Canfield RL, Henderson CR Jr, Cory-Slechta DA, Cox C, Jusko TA, Lanphear $\mathrm{BP}$ : Intellectual impairment in children with blood lead concentrations below 10 microg per deciliter. N Engl J Med 2003, 348:1517-1526.
133. Huang PC, Su PH, Chen HY, Huang HB, Tsai JL, Huang HI, Wang SL: Childhood blood lead levels and intellectual development after ban of leaded gasoline in Taiwan: a 9-year prospective study. Environ Int 2012, 40:88-96.

134. Chen A, Cai B, Dietrich KN, Radcliffe J, Rogan WJ: Lead exposure, IQ, and behavior in urban 5- to 7-year-olds: does lead affect behavior only by lowering IQ? Pediatrics 2007, 119:e650-e658.

135. Wasserman GA, Liu X, Popovac D, Factor-Litvak P, Kline J, Waternaux C, Lolacono N, Graziano JH: The Yugoslavia Prospective Lead Study: contributions of prenatal and postnatal lead exposure to early intelligence. Neurotoxicol Teratol 2000, 22:811-818.

136. Lanphear BP, Hornung R, Khoury J, Yolton K, Baghurst P, Bellinger DC, Canfield RL, Dietrich KN, Bornschein R, Greene T, Rothenberg SJ, Needleman HL, Schnaas L, Wasserman G, Graziano J, Roberts R: Low-level environmental lead exposure and children's intellectual function: an international pooled analysis. Environ Health Perspect 2005, 113:894-899.

137. Baghurst PA, McMichael AJ, Wigg NR, Vimpani GV, Robertson EF, Roberts RJ, Tong SL: Environmental exposure to lead and children's intelligence at the age of seven years. The Port Pirie Cohort Study. N Engl J Med 1992, 327:1279-1284.

138. Chiodo LM, Jacobson SW, Jacobson JL: Neurodevelopmental effects of postnatal lead exposure at very low levels. Neurotoxicol Teratol 2004, 26:359-371.

139. Needleman HL, Riess JA, Tobin MJ, Biesecker GE, Greenhouse JB: Bone lead levels and delinquent behavior. JAMA 1996, 275:363-369.

140. Sciarillo WG, Alexander G, Farrell KP: Lead exposure and child behavior. Am J Public Health 1992, 82:1356-1360.

141. Burns JM, Baghurst PA, Sawyer MG, McMichael AJ, Tong SL: Lifetime low-level exposure to environmental lead and children's emotional and behavioral development at ages 11-13 years. The Port Pirie Cohort Study. Am J Public Health 1999, 149:740-749.

142. Froehlich TE, Lanphear BP, Auinger P, Hornung R, Epstein JN, Braun J, Kahn RS: Association of tobacco and lead exposures with attention-deficit/ hyperactivity disorder. Pediatrics 2009, 124:e1054-e1063.

143. Symeonides C, Ponsonby A-L, Vuillermin P, Anderson V, Sly P: Environmental chemical contributions to ADHD and the externalising disorders of childhood - a review of epidemiological evidence. J Environ Immunol Toxicol 2013, 1:92-104.

144. Sagiv SK, Thurston SW, Bellinger DC, Amarasiriwardena C, Korrick SA: Prenatal exposure to mercury and fish consumption during pregnancy and attention-deficit/hyperactivity disorder-related behavior in children. Arch Pediatr Adolesc Med 2012, 166:1123-1131.

145. Sagiv SK, Thurston SW, Bellinger DC, Tolbert PE, Altshul LM, Korrick SA: Prenatal organochlorine exposure and behaviors associated with attention deficit hyperactivity disorder in school-aged children. Am J Epidemiol 2010, 171:593-601.

146. Wise A, Parham F, Axelrad DA, Guyton KZ, Portier C, Zeise L, Zoeller RT, Woodruff TJ: Upstream adverse effects in risk assessment: a model of polychlorinated biphenyls, thyroid hormone disruption and neurological outcomes in humans. Environ Res 2012, 117:90-99.

147. Jones RL, Homa DM, Meyer PA, Brody DJ, Caldwell KL, Pirkle JL, Brown MJ: Trends in blood lead levels and blood lead testing among US children aged 1 to 5 years, 1988-2004. Pediatrics 2009, 123:e376-e385.

148. Noren K, Meironyte D: Certain organochlorine and organobromine contaminants in Swedish human milk in perspective of past 20-30 years. Chemosphere 2000, 40:1111-1123.

149. Zietz BP, Hoopmann M, Funcke M, Huppmann R, Suchenwirth R, Gierden E: Long-term biomonitoring of polychlorinated biphenyls and organochlorine pesticides in human milk from mothers living in northern Germany. Int J Hyg Environ Health 2008, 211:624-638.

150. What are the trends in exposure to environmental contaminants including across population subgroups and geographic regions? [http://cfpub.epa.gov/eroe/index.cfm?fuseaction=detail.viewlnd\&lv=list. listbyalpha\& $r=224031 \&$ subtop $=208]$

151. Grandjean P, Landrigan PJ: Developmental neurotoxicity of industrial chemicals. Lancet 2006, 368:2167-2178.

152. Zhu SH, Valbo A: Depression and smoking during pregnancy. Addict Behav 2002, 27:649-658.

153. DiPietro JA, Novak MF, Costigan KA, Atella LD, Reusing SP: Maternal psychological distress during pregnancy in relation to child development at age two. Child Dev 2006, 77:573-587. 
154. Way BM, Taylor SE: The serotonin transporter promoter polymorphism is associated with cortisol response to psychosocial stress. Biol Psychiatry 2010, 67:487-492.

155. Davis EP, Sandman CA: The timing of prenatal exposure to maternal cortisol and psychosocial stress is associated with human infant cognitive development. Child Dev 2010, 81:131-148.

156. Rayen I, van den Hove DL, Prickaerts J, Steinbusch HW, Pawluski JL: Fluoxetine during development reverses the effects of prenatal stress on depressive-like behavior and hippocampal neurogenesis in adolescence. PLoS One 2011, 6:e24003.

157. Lee HJ, Kim JW, Yim SV, Kim MJ, Kim SA, Kim YJ, Kim CJ, Chung JH: Fluoxetine enhances cell proliferation and prevents apoptosis in dentate gyrus of maternally separated rats. Mol Psychiatry 2001, 6:610. 725-618.

158. Weikum WM, Brain U, Chau CM, Grunau RE, Boyce WT, Diamond A, Oberlander TF: Prenatal serotonin reuptake inhibitor (SRI) antidepressant exposure and serotonin transporter promoter genotype (SLC6A4) influence executive functions at 6 years of age. Front Cell Neurosci 2013, 7:180

159. Nulman I, Koren G, Rovet J, Barrera M, Pulver A, Streiner D, Feldman B: Neurodevelopment of children following prenatal exposure to venlafaxine, selective serotonin reuptake inhibitors, or untreated maternal depression. Am J Psychiatry 2012, 169:1165-1174.

160. Nulman I, Rovet J, Stewart DE, Wolpin J, Pace-Asciak P, Shuhaiber S, Koren $\mathrm{G}$ : Child development following exposure to tricyclic antidepressants or fluoxetine throughout fetal life: a prospective, controlled study. Am J Psychiatry 2002, 159:1889-1895.

161. Andrews G, Issakidis C, Sanderson K, Corry J, Lapsley H: Utilising survey data to inform public policy: comparison of the cost-effectiveness of treatment of ten mental disorders. Br J Psychiatry 2004, 184:526-533.

162. Jacka FN, Reavley NJ, Jorm AF, Toumbourou JW, Lewis AJ, Berk M: Prevention of common mental disorders: What can we learn from those who have gone before and where do we go next? Aust N Z J Psychiatry 2013, 47:920-929.

163. Prince M, Patel V, Saxena S, Maj M, Maselko J, Phillips MR, Rahman A: No health without mental health. Lancet 2007, 370:859-877.

164. Olds DL, Sadler L, Kitzman H: Programs for parents of infants and toddlers: recent evidence from randomized trials. J Child Psychol Psychiatr 2007, 48:355-391.

165. Olds DL, Kitzman H, Hanks C, Cole R, Anson E, Sidora-Arcoleo K, Luckey DW, Henderson CR, Holmberg J, Tutt RA: Effects of nurse home visiting on maternal and child functioning: age-9 follow-up of a randomized trial. Pediatrics 2007, 120:e832-e845.

166. Olds DL: The nurse-family partnership: an evidence-based preventive intervention. Infant Ment Health J 2006, 27:5-25.

167. Dennis CL: Psychosocial and psychological interventions for prevention of postnatal depression: systematic review. BMJ 2005, 331:15.

168. Fisher JR, Wynter KH, Rowe HJ: Innovative psycho-educational program to prevent common postpartum mental disorders in primiparous women: a before and after controlled study. BMC Publ Health 2010, 10:432.

169. Lumley J, Austin MP, Mitchell C: Intervening to reduce depression after birth: a systematic review of the randomized trials. Int J Technol Assess Health Care 2004, 20:128-144.

doi:10.1186/1741-7015-12-33

Cite this article as: Lewis et al:: Early life programming as a target for prevention of child and adolescent mental disorders. BMC Medicine 2014 12:33

\section{Submit your next manuscript to BioMed Central and take full advantage of:}

- Convenient online submission

- Thorough peer review

- No space constraints or color figure charges

- Immediate publication on acceptance

- Inclusion in PubMed, CAS, Scopus and Google Scholar

- Research which is freely available for redistribution 